\title{
Study of distribution of bone metastases in metastatic breast cancer patients compared to other major cancers
}

\author{
Eman A. Tawfik ${ }^{1}$, Ashraf A. Zytoon' ${ }^{2}$, Suzy F. Gohar ${ }^{1}$ \\ ${ }^{1}$ Clinical Oncology Department, Faculty of Medicine, Menoufia University, ${ }^{2}$ Clinical Radiology \\ Department, Faculty of Medicine, Menoufia University, Egypt.
}

Introduction: Metastatic bone disease is frequent in patients with advanced breast cancer. Although it is not specific for the detection of metastatic bony lesions, bone scan is a sensitive method. The pattern of distribution of bone metastases as detected by bone scan combined with clinical data may help in reaching diagnosis.

Methods: Technetium-99m-methylene diphosphonate skeletal scintigraphy was used for evaluation of distribution pattern of skeletal metastases in patients with breast carcinoma compared to other common cancers. Results: Out of 134 patients with positive bone scan for skeletal deposits, the primary cancer was breast cancer in 81 patients, prostate in 24 , lung in 12 , liver in 8 , urinary bladder in 6 , and head and neck in 3.

Few metastases ( $\leq 3$ deposits) were common in breast cancer, while extensive metastatic lesions $(\geq 10$ deposits $)$ were more common in prostate cancer $(50 \%)$. The most common locations of bone metastases in patients with breast cancer were the spine, pelvic bones, femora, and ribs, respectively.

In prostate cancer patients, spine was the most common site of metastases, especially the lumber region. In lung cancer patients, thoracic spine was the most common site of metastases, while pelvic bones were the most common site in liver cancer patients.

Conclusion: In breast cancer, the most frequent sites of involvement are the spine (especially lumber region), pelvis and axial skeleton, respectively. Spinal and sternal involvements are significantly more in breast cancer than in other malignancies.

Key words: Bone scan, Breast cancer, Skeletal metastases.

Corresponding author: Dr. Suzy F. Gohar, Clinical Oncology Department, Faculty of Medicine, Menoufia University. Shibin el-Kom, Egypt,

E-mail: dr.suzygohar@gmail.com

Received: 12-Jul-2016, Accepted: 1-Sep-2016

\section{INTRODUCTION}

For metastatic carcinomas, skeletal metastases are the third most common following pulmonary and hepatic. In addition, bone metastases may present as the first manifestation of cancer in $25-30 \%$ of cases ${ }^{1}$.

The most common malignant tumors that metastasize to bone are prostate cancer in males and breast cancer in females and lung cancer in both. Also, any malignant tumor can metastasize to bone ${ }^{2}$.

Studying the pattern of distribution of skeletal metastases can help in diagnosis and narrow the diagnostic differentials.

This study aimed to assess the pattern of bone metastases in breast cancer patients compared to other common cancers using Technetium-99m-methylene diphosphonate skeletal scintigraphy. Besides, to explore if there is a specific distribution of bony deposits in breast cancer patients compared to other major malignancies in order to reduce diagnostic differentials.

\section{METHODS}

We studied whole-body bone scans of 150 cancer patients which was done to exclude or assess metastatic bone disease. Anterior and posterior views were obtained with a dual detector gamma camera for patients who had undergone scintigraphy with Tc-99m methylene diphosphonate (600 MBq Tc- 99m MDP).

Bone scans were interpreted as positive for bone metastasis if radiotracer activity of local bone lesion was greater or less than that of adjacent or contralateral normal bone. 


\section{Bone scan results were considered negative when:}

a) No abnormal increased radiotracer uptake was detected.

b) Radiotracer uptake was characterized by medical and benign disease (e.g. arthritis, fracture and trauma).

Bony metastatic lesions in bone scan films were studied regarding their number and pattern of distribution.

Based on the number of metastatic lesions patients were divided into three categories:

I) Patients with few metastatic lesions ( $\leq$ 3lesions)

b) Patients with intermediate metastatic lesions (4- $\leq 9$ lesions)

c) Patients with extensive metastatic lesions $(\geq 10$ lesions)

To describe the pattern of distribution of bone deposits the involved areas were divided into nine portions: skull, sternum, spine, ribs, pelvic bones, sacrum, humeri, scapulae, femora, tibiae and fibulae and clavicles.

Data were computed using SPSS versions 16 for Windows. Continuous data were expressed as mean

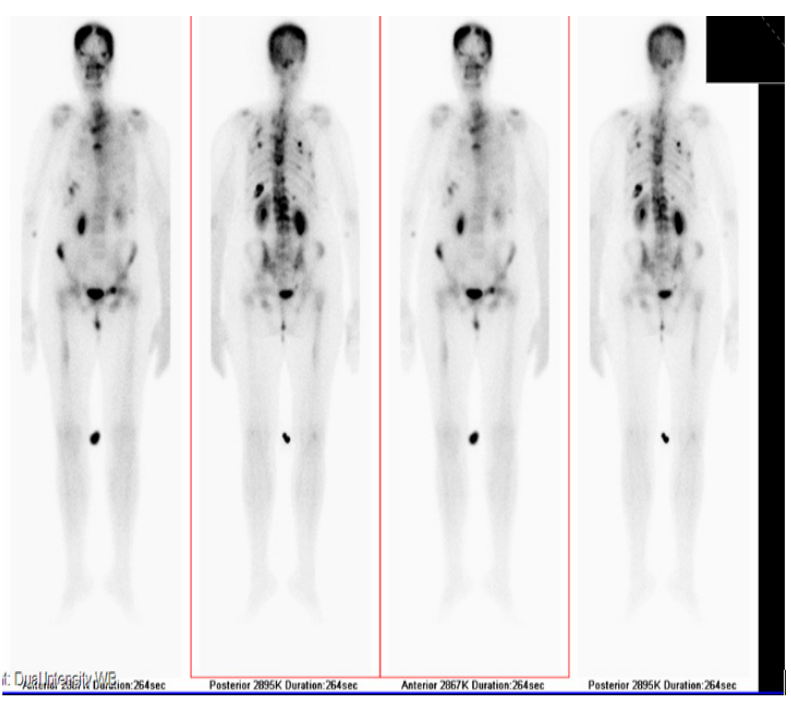

Figure 1: Metastatic breast cancer with extensive bony metastases involving most dorsal and lumber vertebrae, ribs bilaterally pelvic bones and both femora \pm SD while categorical data were expressed as count and percentage. Student $t$ test was used for comparison of continuous data, while Chi-square test was used for categorical data. $\mathrm{P}$ value $<0.05$ was considered statistically significant.

\section{RESULTS}

From January to June, 2015, a total of 597 patients were referred to the Nuclear Medicine Unit at Menoufia Oncology Department for skeletal scintigraphy. One hundred thirty four patients had histologically-proven malignancies and positive scans for bone deposits. Of these 134 patients with positive bone scan, 81 patients had breast cancer, 24 prostate cancer, 12 lung cancer, 8 liver cancer, 6 urinary bladder cancer and 3 head and neck cancer. Demographic characteristics of patients are shown in table 1.

Table 2 shows the distribution of patients with different primary cancer according to onset of metastases (primary or secondary) and number of metastatic lesions (few, intermediate and extensive).

Table 3 shows the distribution of bone metastases according to the primary cancer site. Table 4 compares the distribution sites of breast cancer patients to other patients. In table 5, the distribution is compared between breast cancer patients with primary skeletal metastases and those with secondary skeletal.

Figures 1 to 3 show examples of the studied bone scans.

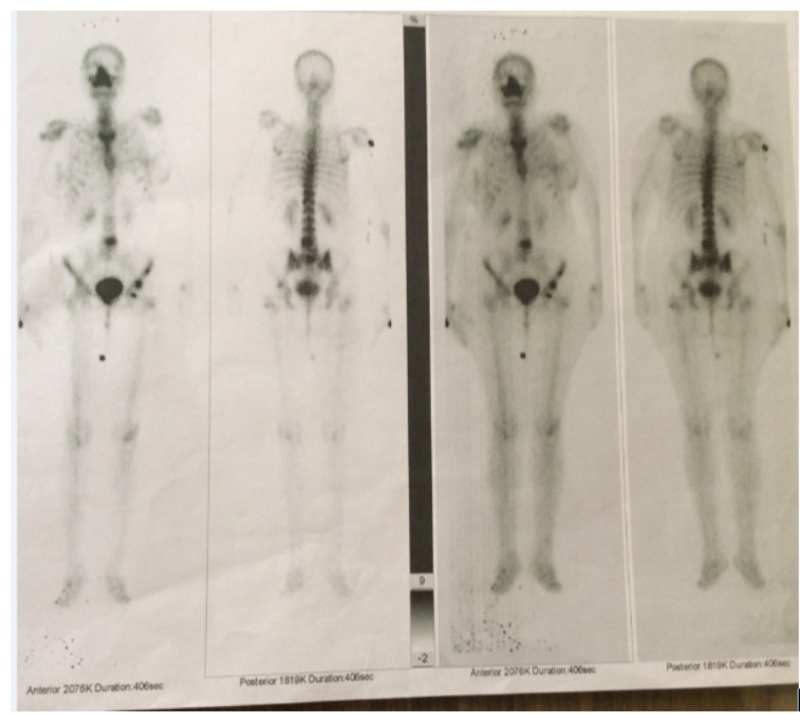

Figure 2: A case of breast cancer with limited metastases 


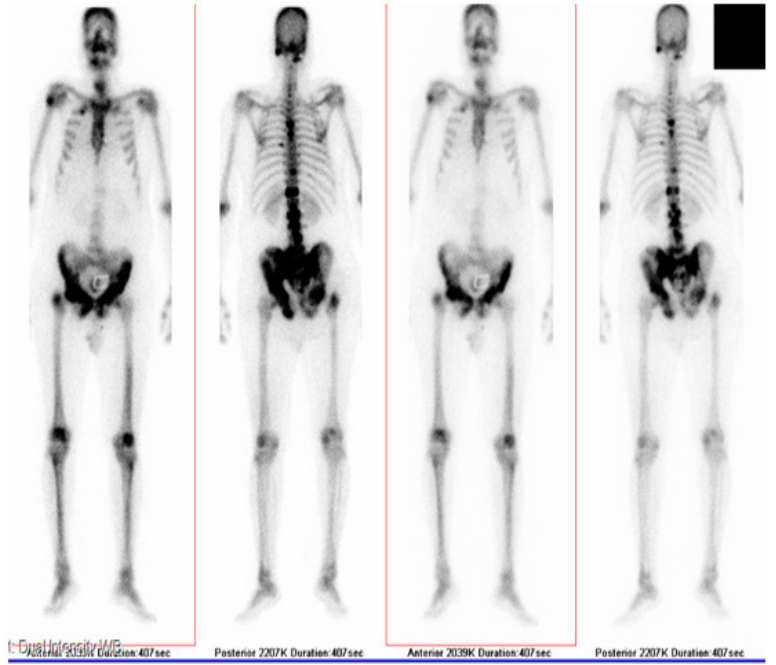

Figure 3: Prostate cancer with extensive bone metastases involving both femora, all pelvic bones, lumber and dorsal vertebrae and ribs.
Table 1: Characteristics of 134 patients.

\begin{tabular}{lcc}
\hline Characteristics & $n$ & \% \\
\hline Age & \multicolumn{2}{c}{$53.88 \pm 11.98$} \\
Mean \pm SD & \multicolumn{2}{c}{$28-90$} \\
Range & \multicolumn{2}{c}{} \\
\hline Sex & 89 & 66.4 \\
Female & 85 & 33.6 \\
Male & & \\
Type of cancer & 81 & 60.4 \\
Breast & 24 & 17.9 \\
Prostate & 12 & 9 \\
Lung & 8 & 6 \\
Liver & 6 & 4.5 \\
Urinary bladder & 3 & 2.2 \\
Head and neck & & \\
\hline
\end{tabular}

Table 2: The onset and number of bone metastases in different cancer types.

\begin{tabular}{|c|c|c|c|c|c|c|c|c|c|c|c|c|}
\hline & \multicolumn{12}{|c|}{ Primary cancer } \\
\hline & \multicolumn{2}{|c|}{$\begin{array}{l}\text { Breast } \\
(\mathrm{n}=81)\end{array}$} & \multicolumn{2}{|c|}{$\begin{array}{l}\text { Liver } \\
(\mathrm{n}=8)\end{array}$} & \multicolumn{2}{|c|}{$\begin{array}{c}\text { Prostate } \\
(n=24)\end{array}$} & \multicolumn{2}{|c|}{$\begin{array}{c}\text { Lung } \\
(\mathrm{n}=12)\end{array}$} & \multicolumn{2}{|c|}{$\begin{array}{c}\text { Bladder } \\
(\mathrm{n}=6)\end{array}$} & \multicolumn{2}{|c|}{$\begin{array}{l}\text { Head \& neck } \\
\quad(\mathbf{n}=\mathbf{3})\end{array}$} \\
\hline & no & $\%$ & no & $\%$ & no & $\%$ & no & $\%$ & no & $\%$ & no & $\%$ \\
\hline \multicolumn{13}{|l|}{ Onset } \\
\hline Primary & 46 & 56.8 & 8 & 100 & 22 & 91.7 & 12 & 100 & 5 & 83.3 & 0 & 0 \\
\hline Secondary & 35 & 43.2 & 0 & 0 & 2 & 8.3 & 0 & 0 & 1 & 16.7 & 3 & 100 \\
\hline \multicolumn{13}{|c|}{ Number of metastases } \\
\hline Few & 37 & 45.7 & 7 & 87.5 & 4 & 16.7 & 7 & 58.3 & 6 & 100 & 2 & 66.7 \\
\hline Intermediate & 29 & 35.8 & 0 & 0 & 8 & 33.3 & 3 & 25 & 0 & 0 & 0 & 0 \\
\hline Extensive & 15 & 18.5 & 1 & 12.5 & 12 & 50 & 2 & 16.7 & 0 & 0 & 1 & 33.3 \\
\hline
\end{tabular}


Table 3: Distribution of bone metastases according to primary cancer.

\begin{tabular}{|c|c|c|c|c|c|c|c|c|c|c|c|c|}
\hline & \multicolumn{12}{|c|}{ Primary cancer } \\
\hline & \multicolumn{2}{|c|}{$\begin{array}{l}\text { Breast } \\
(n=81)\end{array}$} & \multicolumn{2}{|c|}{$\begin{array}{l}\text { Liver } \\
(n=8)\end{array}$} & \multicolumn{2}{|c|}{$\begin{array}{c}\text { Prostate } \\
(n=24)\end{array}$} & \multicolumn{2}{|c|}{$\underset{(n=12)}{\text { Lung }}$} & \multicolumn{2}{|c|}{$\begin{array}{c}\text { Bladder } \\
(n=6)\end{array}$} & \multicolumn{2}{|c|}{$\begin{array}{c}\text { Head \& } \\
\text { neck }(n=3)\end{array}$} \\
\hline & no & $\%$ & no & $\%$ & no & $\%$ & no & $\%$ & No & $\%$ & no & $\%$ \\
\hline Ribs & 18 & 22.2 & 1 & 12.5 & 10 & 41.7 & 4 & 33.3 & 0 & 0 & 1 & 33.3 \\
\hline Scapula & 3 & 3.8 & 0 & 0 & 0 & 0 & 1 & 8.3 & 0 & 0 & 0 & 0 \\
\hline Skull & 7 & 8.6 & 0 & 0 & 5 & 20.8 & 0 & 0 & 0 & 0 & 0 & 0 \\
\hline Sternum & 11 & 13.6 & 0 & 0 & 0 & 0 & 1 & 8.3 & 0 & 0 & 0 & 0 \\
\hline Spine & 68 & 84 & 3 & 37.5 & 21 & 87.5 & 9 & 75 & 0 & 0 & 0 & 0 \\
\hline \multicolumn{13}{|l|}{ Spine site } \\
\hline Cervical & 1 & 1.5 & 0 & 0 & 0 & 0 & 1 & 11.1 & 0 & 0 & 0 & 0 \\
\hline Thoracic & 19 & 27.9 & 0 & 0 & 1 & 4.8 & 5 & 55.6 & 0 & 0 & 0 & 0 \\
\hline Lumbar & 25 & 36.8 & 0 & 0 & 6 & 28.6 & 1 & 11.1 & 0 & 0 & 0 & 0 \\
\hline Cervical + thoracic & 1 & 1.5 & 0 & 0 & 1 & 4.8 & 0 & 0 & 0 & 0 & 0 & 0 \\
\hline Thoracic + lumbar & 19 & 27.9 & 2 & 66.7 & 8 & 38.1 & 1 & 11.1 & 0 & 0 & 0 & 0 \\
\hline Cervical + Thoracic + Lumbar & 3 & 4.4 & 1 & 33.3 & 5 & 23.8 & 1 & 11.1 & 0 & 0 & 0 & 0 \\
\hline Sacrum & 14 & 17.3 & 1 & 12.5 & 8 & 33.3 & 1 & 8.3 & 0 & 0 & 0 & 0 \\
\hline Humeri & 13 & 16 & 2 & 25 & 7 & 29.2 & 3 & 25 & 4 & 66.7 & 0 & 0 \\
\hline \multicolumn{13}{|l|}{ Humeri site } \\
\hline Upper shaft & 11 & 84.6 & 1 & 50 & 6 & 85.7 & 3 & 100 & 3 & 75 & 0 & 0 \\
\hline Lower shaft & 2 & 15.4 & 1 & 50 & 0 & 0 & 0 & 0 & 1 & 25 & 0 & 0 \\
\hline Whole length & 0 & 0 & 0 & 0 & 1 & 14.3 & 0 & 0 & 0 & 0 & 0 & 0 \\
\hline Femora & 25 & 30.9 & 0 & 0 & 10 & 41.7 & 2 & 16.7 & 1 & 16.7 & 1 & 33.3 \\
\hline \multicolumn{13}{|l|}{ Femora site } \\
\hline Upper shaft & 20 & 80 & 0 & 0 & 9 & 90 & 1 & 50 & 1 & 100 & 1 & 100 \\
\hline Lower shaft & 3 & 12 & 0 & 0 & 9 & 90 & 1 & 50 & 1 & 100 & 1 & 100 \\
\hline Whole length & 2 & 8 & 0 & 0 & 1 & 10 & 1 & 50 & 0 & 0 & 0 & 0 \\
\hline Tibiae & 2 & 2.5 & 0 & 0 & 0 & 0 & 0 & 0 & 0 & 0 & 0 & 0 \\
\hline Pelvis & 30 & 37.0 & 4 & 50 & 16 & 66.7 & 3 & 25 & 2 & 33.3 & 1 & 33.3 \\
\hline Ilium & 4 & 13.3 & 1 & 25 & 7 & 43.8 & 0 & 0 & 1 & 50 & 1 & 100 \\
\hline Pubis & 1 & 3.3 & 0 & 0 & 0 & 0 & 0 & 0 & 1 & 50 & 0 & 0 \\
\hline Ischium & 4 & 13.3 & 0 & 0 & 0 & 0 & 0 & 0 & 0 & 0 & 0 & 0 \\
\hline Hip & 6 & 20.0 & 1 & 25 & 1 & 6.2 & 0 & 0 & 0 & 0 & 0 & 0 \\
\hline Ilium + pubis & 1 & 3.3 & 0 & 0 & 0 & 0 & 1 & 33.3 & 0 & 0 & 0 & 0 \\
\hline Ilium + ischium & 2 & 6.7 & 0 & 0 & 1 & 6.2 & 0 & 0 & 0 & 0 & 0 & 0 \\
\hline Ilium + hip & 9 & 30.0 & 0 & 0 & 1 & 6.2 & 0 & 0 & 0 & 0 & 0 & 0 \\
\hline Ilium + obturator & 1 & 3.3 & 0 & 0 & 0 & 0 & 0 & 0 & 0 & 0 & 0 & 0 \\
\hline Hip + ischium & 0 & 0 & 0 & 0 & 2 & 12.5 & 0 & 0 & 0 & 0 & 0 & 0 \\
\hline Acetabulum & 1 & 3.3 & 1 & 25 & 0 & 0 & 2 & 66.7 & 0 & 0 & 0 & 0 \\
\hline $\begin{array}{l}\text { Ischium + ilium + } \\
\text { acetabulum + hip }\end{array}$ & 1 & 3.3 & 0 & 0 & 2 & 12.5 & 0 & 0 & 0 & 0 & 0 & 0 \\
\hline $\begin{array}{l}\text { Ischium }+ \text { ilium }+ \\
\text { acetabulum + pubis }\end{array}$ & 0 & 0 & 0 & 0 & 2 & 12.5 & 0 & 0 & 0 & 0 & 0 & 0 \\
\hline Pubis + acetabulum & 0 & 0 & 1 & 25 & 0 & 0 & 0 & 0 & 0 & 0 & 0 & 0 \\
\hline
\end{tabular}


Table 4: Comparison between breast cancer patients and other patients as regard to bone metastases distribution.

\begin{tabular}{|c|c|c|c|c|c|c|}
\hline & \multicolumn{4}{|c|}{ Cancer } & \multirow{3}{*}{$\chi^{2}$} & \multirow{3}{*}{ p-value } \\
\hline & \multicolumn{2}{|c|}{ Breast $(n=81)$} & \multicolumn{2}{|c|}{ Others $(n=53)$} & & \\
\hline & $n$ & $\%$ & $n$ & $\%$ & & \\
\hline \multicolumn{7}{|l|}{ Origin } \\
\hline - $\quad$ Primary & 46 & 56.8 & 46 & 56.8 & 15.34 & $<0.001$ \\
\hline - $\quad$ Secondary & 35 & 43.2 & 35 & 43.2 & & \\
\hline \multicolumn{7}{|l|}{ Metastasis } \\
\hline - $\quad$ Few & 37 & 45.7 & 26 & 49.1 & 4.39 & 0.111 \\
\hline - Intermediate & 29 & 35.8 & 11 & 20.8 & & \\
\hline - $\quad$ Extensive & 15 & 18.5 & 16 & 30.2 & & \\
\hline Ribs & 18 & 22.2 & 16 & 30.2 & 1.07 & 0.3 \\
\hline Scapula & 3 & 3.8 & 1 & 1.9 & 0.35 & 0.55 \\
\hline Skull & 7 & 8.6 & 5 & 9.4 & 0.02 & 0.875 \\
\hline Sternum & 11 & 13.6 & 1 & 1.9 & 5.37 & 0.028 \\
\hline Spine & 68 & 84 & 33 & 62.3 & 8.11 & 0.004 \\
\hline \multicolumn{7}{|l|}{ Spine site } \\
\hline - Cervical & 1 & 1.5 & 1 & 3 & 0.25 & 0.8 \\
\hline - Thoracic & 19 & 27.9 & 6 & 18.2 & 0.81 & 0.415 \\
\hline - Lumber & 25 & 36.8 & 7 & 21.2 & 1.35 & 0.176 \\
\hline - $\quad \mathrm{Cer}+\mathrm{Th}$ & 1 & 1.5 & 1 & 3 & 0.25 & 0.8 \\
\hline - $\quad$ Th+Lum & 19 & 27.9 & 11 & 33.3 & 0.33 & 0.745 \\
\hline - $\quad$ Cer+Th+Lumb & 3 & 4.4 & 7 & 21.2 & 2.30 & 0.021 \\
\hline - Cervical & 5 & 6.2 & 8 & 15.1 & 2.91 & 0.088 \\
\hline - Thoracic & 41 & 50.6 & 24 & 45.3 & 0.36 & 0.546 \\
\hline - $\quad$ Lumber & 46 & 56.8 & 24 & 45.3 & 1.70 & 0.192 \\
\hline Sacrum & 14 & 17.3 & 10 & 18.9 & 0.05 & 0.815 \\
\hline Humeri & 13 & 16.0 & 16 & 30.2 & 3.77 & 0.052 \\
\hline \multicolumn{7}{|l|}{ Site humeri } \\
\hline - Upper shaft & 11 & 84.6 & 13 & 81.2 & 0.86 & 0.649 \\
\hline - Lower shaft & 2 & 15.4 & 2 & 12.5 & & \\
\hline - Whole length & 0 & 0 & 1 & 6.2 & & \\
\hline Femora & 25 & 30.9 & 14 & 26.4 & 0.30 & 0.579 \\
\hline \multicolumn{7}{|l|}{ Site Femora } \\
\hline - Upper shaft & 20 & 80 & 12 & 85.7 & 2.06 & 0.357 \\
\hline - Lower shaft & 3 & 12 & 0 & 0 & & \\
\hline - Whole length & 2 & 8 & 2 & 14.3 & & \\
\hline Tibii & 2 & 2.5 & 0 & 0.0 & $* 1.32$ & 0.518 \\
\hline Pelvis & 30 & 37.0 & 26 & 49.1 & 1.90 & 0.168 \\
\hline - Iliac & 4 & 13.3 & 10 & 38.5 & 3.17 & 0.001 \\
\hline - $\quad$ Pubis & 1 & 3.3 & 1 & 3.8 & 0.33 & 0.473 \\
\hline - Ischium & 4 & 13.3 & 0 & 0 & 2.44 & 0.014 \\
\hline - $\quad$ Hip & 6 & 20 & 2 & 7.7 & 1.7 & 0.089 \\
\hline - $\quad$ Iliac + pubis & 1 & 3.3 & 1 & 3.8 & 0.33 & 0.743 \\
\hline - $\quad$ Iliac + ischium & 2 & 6.7 & 1 & 3.8 & 0.33 & 0.74 \\
\hline - $\quad$ Iliac + hip & 9 & 30 & 1 & 3.8 & 3.51 & 0.0004 \\
\hline - $\quad$ Iliac + obturator & 1 & 3.3 & 0 & 0 & 0.7 & 0.481 \\
\hline - $\quad$ Hip + ischium & 0 & 0 & 2 & 7.7 & 2.02 & 0.043 \\
\hline - Acetabulum & 1 & 3.3 & 3 & 11.5 & 1.52 & 0.128 \\
\hline - $\quad$ Ischium + ileum + acetabulum + pubis & 1 & 3.3 & 2 & 7.7 & 0.73 & 0.462 \\
\hline - $\quad$ Ischium + ilium + acetabulum + pubis & 0 & 0 & 2 & 7.7 & 2.02 & 0.043 \\
\hline - $\quad$ Pubic + acteabulum & 0 & 0.0 & 1 & 3.8 & 1.04 & 0.297 \\
\hline
\end{tabular}

"Fisher's exact 
Table 5: The distribution of bone metastases in breast cancer patients according to the onset of metastases (primary vs. secondary).

\begin{tabular}{|c|c|c|c|c|c|c|c|}
\hline & & \multicolumn{4}{|c|}{ Onset of metastases } & \multirow{3}{*}{$\mathbf{X}^{2}$} & \multirow{3}{*}{ P-value } \\
\hline & & \multicolumn{2}{|c|}{ primary } & \multicolumn{2}{|c|}{ secondary } & & \\
\hline & & No & $\%$ & No & $\%$ & & \\
\hline \multirow{2}{*}{ Ribs } & Yes & 10 & 21.7 & 8 & 22.9 & \multirow{2}{*}{0.014} & \multirow{2}{*}{ NS } \\
\hline & No & 36 & 78.3 & 27 & 77.1 & & \\
\hline \multirow{2}{*}{ Scapula } & Yes & 2 & 4.4 & 1 & 2.9 & \multirow{2}{*}{0.137} & \multirow{2}{*}{ NS } \\
\hline & No & 43 & 95.6 & 34 & 97.1 & & \\
\hline \multirow{2}{*}{ Skull } & Yes & 5 & 10.9 & 2 & 5.7 & \multirow{2}{*}{0.669} & \multirow{2}{*}{$<0.05$} \\
\hline & No & 41 & 89.1 & 33 & 94.3 & & \\
\hline \multirow{2}{*}{ Sternum } & Yes & 5 & 10.9 & 6 & 17.1 & \multirow{2}{*}{0.667} & \multirow{2}{*}{$<0.05$} \\
\hline & No & 41 & 89.1 & 29 & 82.9 & & \\
\hline \multirow{2}{*}{ Pelvis } & Yes & 18 & 39.1 & 14 & 40 & \multirow{2}{*}{0.006} & \multirow{2}{*}{$<0.05$} \\
\hline & No & 28 & 60.9 & 21 & 60 & & \\
\hline \multirow{10}{*}{ Pelvis Site } & Ilium & 2 & 11.8 & 2 & 15.4 & \multirow{10}{*}{9.299} & \multirow{10}{*}{$<0.05$} \\
\hline & Pubis & 0 & 0 & 1 & 7.7 & & \\
\hline & Ischium & 3 & 17.6 & 1 & 7.7 & & \\
\hline & Hip & 4 & 23.5 & 2 & 15.4 & & \\
\hline & Ilium + pubis & 0 & 0 & 1 & 7.7 & & \\
\hline & Ilium + ischium & 2 & 11.8 & 0 & 0 & & \\
\hline & Ilium + hip & 3 & 17.6 & 6 & 46.2 & & \\
\hline & Ilium + obturator & 1 & 5.9 & 0 & 0 & & \\
\hline & Acetabulum & 1 & 5.9 & 0 & 0 & & \\
\hline & Ischium + ilium + acetabulum + hip & 1 & 5.9 & 0 & 0 & & \\
\hline Snine & Yes & 41 & 89.1 & 27 & 77.1 & 2120 & $<005$ \\
\hline Spine & No & 5 & 10.9 & 8 & 22.9 & 2.120 & $<0.03$ \\
\hline & Cervical & 1 & 2.4 & 0 & 0 & & \\
\hline & Thoracic & 13 & 31.7 & 6 & 22.2 & & \\
\hline & Lumber & 16 & 39 & 9 & 33.3 & & \\
\hline Spine Site & Cervical + thoracic & 0 & 0 & 1 & 3.7 & 4.221 & NS \\
\hline & Thoracic + lumbar & 9 & 22 & 10 & 37 & & \\
\hline & Cervical + thoracic + lumbar & 2 & 4.9 & 1 & 3.7 & & \\
\hline C & Yes & 7 & 15.2 & 7 & 20 & 0218 & NS \\
\hline Sacrum & No & 39 & 84.8 & 28 & 80 & 0.318 & NS \\
\hline Humari & Yes & 9 & 19.6 & 4 & 11.4 & 0077 & $<005$ \\
\hline Humeri & No & 37 & 80.4 & 31 & 88.6 & 0.977 & $<0.05$ \\
\hline Humeri site & Upper shaft & 8 & 88.9 & 3 & 75 & 0410 & NS \\
\hline 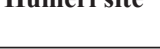 & Lower shaft & 1 & 11.1 & 1 & 25 & & \\
\hline Foman & Yes & 17 & 37 & 11 & 31.4 & 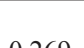 & NG \\
\hline Femora & No & 29 & 63 & 24 & 68.6 & 0.269 & NS \\
\hline & Upper shaft & 13 & 86.7 & 7 & 70 & & \\
\hline Femora site & Lower shaft & 2 & 13.3 & 1 & 10 & 3.264 & $<0.05$ \\
\hline & Whole length & 0 & 0 & 2 & 20 & & \\
\hline Tibiae & Yes & 1 & 2.2 & 1 & 2.9 & 0.039 & NS \\
\hline & No & 45 & 97.8 & 34 & 97.1 & & \\
\hline
\end{tabular}




\section{DISCUSSION}

It is important for both radiologist and nuclear medicine physician to know the pattern of distribution of metastatic skeletal deposits in breast cancer as it may help them to comment on the nature of lesions within the skeleton. Furthermore, this may aid in expecting the sites of possible skeletal related events and its early management.

Out of the studied 134 patients with positive bone scan for skeletal deposits, 81 cases had breast cancer and 53 cases had other solid malignancies. As regard number of bone metastases, few metastases ( $\leq 3$ deposits) were more common in breast cancer patients $(45.7 \%)$ while extensive metastatic lesions ( $\geq 10$ deposits) were more common in prostate cancer patients $(50 \%)$.

As regard the site of bone metastases, the current study showed that the main sites of metastases are the ribs, pelvis and spine. Proximal femora were the most commonly involved sites in the extremities. These results are in agreement with those of Kakhki et al ${ }^{3}$. This can be explained by the fact that sinusoidal vascular spaces in the red bone marrow represent attractive sites for metastases as it is easily penetrated by cancer cells.

The most common location of bone metastases on scan images of patients with breast cancer was the spine, especially the lumber region; which is consistent with the results of Kakhki et al ${ }^{3}$. However, Afzal et $a l^{4}$ and Wang et $a l^{5}$ noted that the highest numbers were in the spine, mainly the thoraco-lumbar vertebrae. This is on contrary to our findings, where the lumber vertebrae were the most common metastatic site.

In our study, pelvic bones were the second most common metastatic sites in breast cancer, followed by femora (especially the proximal parts) followed by ribs. While, Kakhki et al ${ }^{3}$ reported that the second most common sites in breast cancer patients were the ribs and sternum. Also, Afzal et al ${ }^{4}$ and Wang et $a l^{5}$ reported ribs as the second most common site then pelvic bones. Bieki et $\mathrm{al}^{6}$ studied the pattern of bone metastases in breast cancer patients and found that the commonest sites were the pelvis and hip, lumbar and thoracic vertebrae and ribs. The difference in distribution between our study and that of other studies may be due to the difference in the number of patients studied.

In prostate cancer, we found the spinal vertebrae as the most common site especially the lumber region; consistent with the results of Kakhki et $a l^{3}$.
An explanation for that is the spread of prostatic malignant cells via the Batson venous plexus to the pelvis and spine bones earlier in the course of the disease followed later by other skeletal sites. Similar results were obtained by Wang et al ${ }^{5}$ and Zytoon et $a l^{7}$ who found that metastatic bony lesions of prostate cancer are located mainly in the spine. The second most common metastatic sites in prostate cancer patients in our study were in the pelvic bones, which is in agreement with Kakhki et $a l^{3}$ and Wang et $a l^{5}$. On the other hand, Zytoon et $a l^{7}$ found the ribs and femora to be the second and third frequently involved sites. This may be due to the inclusion of relatively few prostatic cancer patients in our study (24 patients) in comparison to Zytoon et $\mathrm{al}^{7}$ who included 150 patients. Other researchers reported a different pattern of bone metastases in prostate cancer patients. In 2010, Bieki et al ${ }^{6}$ reported that the most common sites in prostate cancer patients were pelvis, thoracic vertebrae, proximal femur, ribs and lumbar vertebrae; respectively.

Although, in our study the number of lung cancer patients was small (12 patients), we found that the most common region was thoracic spine mostly due to direct invasion by tumor mass. While, previous researchers found that the ribs then the spinal region were the most common sites $^{3,8}$ which can be attributed to direct tumor invasion.

Pelvic bones were the most common site in liver cancer patients; while, upper humeral metastases were the most common in urinary bladder cancer patients.

\section{Conclusions and recommendations}

In breast cancer patients, the most common involved bone metastases sites were spine (especially lumber region), pelvic bones and femora; respectively. Compared to other types of cancers, spine, sternum and iliac bone involvement were significantly more common in breast cancer.

Further research investigating the clinical application of studying the pattern of bone metastases is recommended.

\section{REFERENCES}

1. Piccioli A, Maccauro G, Spinelli MS, Biagini R, Rossi B. Bone metastases of unknown origin: epidemiology and principles of management. J Orthop Traumatol. 2015; 16(2): 81-86.

2. Piccioli A. Breast cancer bone metastases: an orthopedic emergency. J Orthop Traumatol. 2014; 15(2): 143-144. 
3. Kakhki VR, Anvari K, Sadeghi R, Mahmoudian AS, Torabian-Kakhki M. Pattern and distribution of bone metastases in common malignant tumors. Nucl Med Rev Cent East Eur. 2013; 16(2): 66-69.

4. Afzal MS, Akhtar MS, Shahid A. Pattern of distribution of metastatic lesions within skeleton in patients with breast carcinoma of Faisalabad and its vicinity. APMC. 2009; 3(1): 13-18.

5. Wang CY, Wu GY, Shen MJ, Cui KW, Shen Y. Comparison of distribution characteristics of metastatic bone lesions between breast and prostate carcinomas. Oncol Lett. 2013; 5(1): 391-397.
6. Beiki D, Fallahi B, Khodaparast M, et al. Scintigraphic patterns of bone metastases in 146 patients with different types of cancers. Eur J Nucl Med Mol Imaging. 2010; 37 (Suppl 2): S470-S471.

7. Zytoon AA, Tawfek EA, Elwakil AM, Aladle GI. Evaluation of Distribution Features of Bone Metastases by Bone Scintigraphy in Prostate Cancer. Int $\mathrm{J}$ Med Imaging. 2015; 3 (6): 137-142.

8. Wang C, Shen Y, Zhu S. Distribution Features of Skeletal Metastases: A Comparative Study between Pulmonary and Prostate Cancers. PLoS One. 2015; 10(11): e0143437. 